\title{
DIE PROFESIE VAN NAHUM, OPNUUT VERTAAL
}

1- 1 Die godspraak oor Ninevé. Die boek van die gesig van Nahum, die Élkosiet.

'N Wreker is die HERE! H. 1:2-10.

2 'n Jaloerse God en 'n wreker is die HERE.

'n wreker is die HERE en vol gramskap:

n wreker is die HERE vir sy teëstanders

en Hy behou (die toorn) teen sy ryande.

3 Die HERE is lankmoedig, maar groot van krag, en geensins laat die HERE ongestraf bly nie.

In warrelwind en storm is sy weg.

en die wolke is die stof van sy voete.

4 Hy dreig die see en maak dit droog

en al die riviere laat $\mathrm{Hy}$ opdroog:

Basan en Karmel 'kwyn weg'

en die groenigheid van Libanon verwelk.

5 Die berge bewe voor Hom en die heuwels smelt weg:

en die aarde rys op voor sy sangesig, ja, die wéreld en al sy bewoners.

6 Voor sy grimmigheid wie sal kan standhou? en wie is bestand teen die gloed van sy toorn?

Sy gramskap word uirgegiet soos 'n vuur, en die rotse word stukkend geruk deur Hom.

7 Goed is die HERE.

n toevlug in die dag van benoudheid, en Hy ken die wat by Hom skuil.

8 Maar met 'n oorstromende vloed maak $\mathrm{Hy}$ ' $\mathrm{n}$ end aan die plek van (die stad) en sy vyande vervoig $\mathrm{Hy}$ in die duisternis in.

9 Wat wil julle beraam teen die HERE?

n End maak Hy daaraan: die benoudheid sal nie tweemaal opkom nie.

10 Want al is hulle saamgevleg soos dorings,

en soos hulle drank so deur-en-deur nat hulle word soos droë stoppels volkome verteer. 
11 Van jou (o stad) het een uitgegaan wat kwaad teen die HERE beraam het, wat snode planne gemaak het.

12 So sê die HERE:

$\mathrm{Al}$ is hulle in volle krag en só groot in getal, tog sal hulle net só afgemaai word en 'vergaan'.-

Ek het jou verneder, Ek sal jou nie meer verneder nie;

13 maar nou sal Ek sy juk van jou af verbreek, en jou stroppe stukkend ruk.-

14. Maar die HERE verorden oor jóu:

Van jou naam sal daar nie meer gesaai word nie; uit die huis van jou god sal Ek uitroei die gesnede en gegote beelde;

Ek berei jou graf want jy is te lig bevind.-

$15 \mathrm{Kyk}$, op die berge die voete van hom wat goeie boodskap bring, wat vrede laat hoor:

Vier jou feesdae, o Juda, betaal jou geloftes!

Want nooit weer sal die snoodaard deur jou deurtrek nie; hy is heeltemal uitgeroei! -

2- 1 in Verstrooier trek jou op: bewaak die vesting,

kyk uit langs die weg, versterk die lende, span jou krag tot die uiterste in!-

2 Want die HERE gaan die heerlikheid van Jakob herstel netsoos die heerlijkheid van Israel; want verwoesters het hulle verwoes en hulle wingerdlote verniel.-

Die val van Ninevé aAngekondig, H. 2:3-13.

Die bestormer, vs. 3-5.

3 Die skild van sy helde is rooi geverf, die dapper manne in skarlaken gekleed, 
met die glans van staal (skitter) die strydwaens op die dag as hy klaar maak.

en die spiese word geswaai.

4 Langs die paaie raas die waens, hulle jaag rond oor die vlaktes: hulle voorkomste is soos fakkels, soos bliksemstrale skiet hulle heen en weer.

5 Hy 'ontbied' sy magtiges, hulle struikel in hulle vaart, hulle hardloop na die muur, en die stormdak word opgerig.

$$
\text { Die vlug. vs. 6-8. }
$$

6 Die rivierpoorte word oopgemaak en die paleis smelt weg.

7 En dit is beslis : sy word ontbloot, weggevoer, en haar slavinne klae met 'n stem soos van duiwe en slaan op hulle bors.

8 En Ninevé soos 'n watervywer wie se 'waters' weguloei.

Staan tog, staan!

Maar niemand keer om nie.

Plundering en verwoesting, is. 9 en 10.

9 Roof silwer, roof goud!

En daar is geen einde aan die voorraad, in rykdom van allerlei kosbare dinge!

10 Woesheid, woesteny, verwoesting!

En die hart versmelt en knieë wankel, en kramp in al die lende

en almal se aangesigte word bleek.

Die leeunes word uitgeroei, vs. 11-13.

11 Waar is nou die lêplek van' die leeus, wat die 'hol' was van die jong leeus, waar die leeu gegaan het, die leeuwyfie, die klein leeutjie sonder dat iemand skrik maak?

12 Die leeu wat vir sy kleintjies geroof het, en vir sy wyfies gewurg het. 
wat sy gate met roof gevul het en sy lêplekke met buit?

13 Kyk, Ek het dit teen jou, spreek die HERE van die leërskare, en Ek laat 'jou skuilplek' in rook opgaan; en jou jong leeus sal die swaard verslind, en Ek sal jou roof van die aarde verdelg en die stem van jou gesante sal nie meer gehoor word nie.

Die ondergang van Ninevé, H. 3.

Die moordstad bestorm, us. 1-3.

3- 1 Wee die bloedstad wat enkel bedrog is, vol van prooi, rowery kry geen end nie!

2 Hoor, die sweep! En hoor die gedreun van wiele!

En perde wat jaag, en waens wat stamp!

3 Ruiters op in galop en geglinster van swaarde en geblits van spiese!

En in menigte gewondes en hope dooies, en geen end aan die lyke niein mens struikel oor hulle lyke!

Die mooi hoet onteer, vs. 4-7.

4 Weens die veelheid van hoererye van die hoer mooi van bevalligheid, 'n meesteres in towerpraktyke, wat nasies met haar hoererye verkoop het en geslagte met haar towerkunste.

5 Kyk, Ek het dit teen jou, spreek die HERE van die leërskare, en Ek sal jou slippe optel oor jou aangesig en die nasies jou naaktheid laat sien en koninkryke jou skande.

6 En Ek sal vuilgoed op jou gooi en jou aan minagting prysgee, en jou tot ' $n$ skouspel maak. 
7 En elkeen wat jou sien sal wegvlug van jou af en sê:

Verwoes is Ninevé!

Wie sal met haar medelye hê?

Vanwaar sal ek troosters

gaan soek vir jou?

Die lot van Thebe sal Ninevé tref, vs. 8-10.

8 Is jy beter as No-Amon

Wat gelê het aan die Nylstrome, met waters rondom hom,

wie se voorskans die groot water was, 'waters' sy muur?

9 Kus was sy krag en Egipte

en dit sonder getal,

Put en Libiërs

was tot 'sy' hulp.

10 Tog moes hy in ballingskap.

in gevangenskap gaan,

tog is sy kinders verpletter

by al die straathoeke,

en oor sy edeles

is die lot gewerp.

en al sy groot manne

is met kettings geboei!

11 Ook jy sal dronk word,

beneweld wees,

ook jy sal 'n toevlug

soek teen die vyand.

$12 \mathrm{Al}$ jou vestings is soos vyebome met voorvye :

as in mens skud dan val hulle op die mond van die eter.

13 Kyk, jou volk binne-in jou

is soos vroue,

vir jou vyande is wyd oopgemaak

die poorte van jou land;

die vuur het jou grendels verteer.

Teenstand en groot getalle tevergeefs! vs. 13-17.

14 Skep vir jou water vir die beleëring, versterk jou vestings; 
gaan in die modder,

en trap klei,

gryp die steenvorm!

15 Daar sal die vuur jou verteer, die swaard jou uitroei-

dit sal jou verteer soos voetgangers;

al vermenigvuldig jy soos voetgangers,

al veimenigvuldig jy soos treksprinkane,

16 al maak jy jou koopmans meer talryk

as die sterre van die hemel -

die voetgangers vervel en vlieg weg!

17 Jou opsigters is soos treksprinkane,

en jou amptenare soos sprinkaanswerms, wat in die mure skuil

op 'n koue dag -

die son gaan op en hulle vlieg weg,

en die plek waar hulle beland bly onbekend.

Dodesang oor Assirië, vs. 18 en 19.

18 Jou herders sluimer, o koning van Assirië, jou edeles lê neer,

jou volk is verstrooi op die berge, en niemand versamel hulle nie.

19 Daar is geen herstel vir jou instorting nie, ongeneeslik is jou verwonding;

almal wat die tyding omtrent jou verneem, klap hulle hande saam oor jou, want oor wie het jou boosheid nie voortdurend getrek nie?

As in moontlik welkome, in alle geval meer leesbare variasie in die reeks Teksverbeteringe van die Afrikaanse Bybel (sien Herv. Teol. Studies IIde jaarg. bl. 27 en 179 vv.) bied ons hierby 'n nuwe bewerking in Afrikaans van die profesie van Nahum. Dit sluit soveel as maar moontlik is aan by die gebruiklike Afrikaanse Bybelvertaling (in die volgende met die afkorting $A B$ aangedui) waarvan ons die verdienste graag erken. Tog is daar van die 47 verse van hierdie kort Bybelboek slegs 11 waarin ons nie graag kleiner of groter veranderings in die vertaling sou wil aanbeveel nie.

Die boek van Nahum verdien so'n noukeurige revisie alleen reeds as deel van die Heilige Skrif en van wat miskien wel sy kern genoem kan word: die Profesie. Maar ook om sy besondere inhoud en vorm. Dit sou verleidelik wees om hierop uitvoeriger in te gaan. Maar 
die bedoeling van hierdie artikel is nie om $n$ bespreking van die waarde, die godsdienstige en letterkundige, van hierdie klein dog kosbare geskrif te gee nie. Wat sy poëtiese waarde betref haal ek slegs aan die woorde van RoBERT LowTH (1710-1787, professor in die digkuns te Oxford, later biskop van Londen) wat in die XXIste lesing van sy grondleende geskrif oor die Hebreeuse digkuns De sacra poesi Hebraeorum by die behandeling van die besondere kenmerke van die afsonderlike profetiese geskrifte na van die profeet Miga opgemerk te hê: ,in baie opsigte verhewe en vurig en seer poëties" voortgaan: „Maar van al die Klein Profete skyn niemand te ewenaar die verhewenheid, gloed en stoutmoedige gees van Nahum nie. Voeg hierby dat sy profesie in suiwere en egte digwerk is; die aanvang is pragtig en eenvoudig majestueus; die uitgebreide beskrywing van die toerusting tot die verwoesting van Ninevé en van die verwoesting self word in die gloeiendste kleure tot uitdrukking gebring en besit ' $n$ bewonderingswaardige lewendigheid van beskrywing en nadruklikheid".')

En wat sy inhoud betref, teenoor die kleinering en misverstand van die profeet soos 'n tyd lank in kommentare gebruiklik (vgl. bv. wat J. M. Powis SMith in sy origens uitnemende verklaring in The International Critical Commentary, Edinburg. 1928, 2nd impr. meen te mag sê: „In Nahum vind 'n verteenwoordiger van die ou, enghartige en oppervlakkige profetisme sy plek in die kanon van die Skrif" aangesien hy Nahum beskou as een van die heils- en volksprofete waarteen die egte profete soos Jeremia so'n felle stryd gevoer het) stel ons liewer 'n getuienis soos van F. Horst in die Handbuch zum Alten Testament van O. Eissefeldt e.a. (Tübingen 1938, I, 14, bl. 155): Nahum se blik is met uiterste gespannenheid op God en sy handele gerig, soseer dat buite hierdie geweldige historiese gebeure niks in sy gesigsveld kom nie; dit gaan in hierdie profesie in die diepste kern om die stryd en segepraal van God; dis geen haatgesang teen 'n nasionale vyand nie, maar 'n dreigwoord teen die oormoedige, God trotserende wêreldmag. Een sekerheid deurtrek, ja deurtril die siel van die profeet: dat die Here die tiranneburg sal verpletter en dat hierdie gebeurtenis onmiddellik voor die deur staan.

Nahum se prediking van die Goddelike geregtigheid wat op beslissende momente in die wêreldgeskiedenis as straffende vergelding so onmiskenbaar en onontkombaar tot uiting kom, het sy aktualiteit

1) Verum ex omnibus minoribus prophetis nemo videtur aequare sublimitatem, ardorem, et audaces spiritus Nahumi. Adde quod eius vaticinium integrum ac justum est poëma; exordium magnificum est et plane augustum: apparatus ad excidium Ninivae, eijusque excidii deschiptio et amplificatio, ardentissimis coloribus exprimitur, et admirabilem habet evidentiam et pondus ILowth, 1.c., ed. sec., Goettingae 1770, p. 434; ed. Oxford, p. 281 s.. 
in die loop van die eeue en tot in ons eie tyd toe nie verloor nie. En die pragtig-bewoë vorm waarin hy die oortuiging wat hom van Godsweë in die siel gegrif is, tot uitdrukking bring, verdien die uiterste sorg by die weergawe van sy vurig-besielde woorde is ons eie taal.

Die AB volg gewoonlik die Textus Receptus, d.i. die sedert die hegin van die 16de eeu in gedrukte Bybels voorkomende teks (sien hieroor ons artikel in H.T.S. II, 2, April 1945, „Die organiese eenheid van objektiewe Bybelondersoek", bl. 49 vv., besonder bl. 53 vv.). Dis merkwaardig om op te merk dat in die kort geskrif van Nahum die $\mathrm{AB}$ tog in 5 gevalle daarvan afwyk. In $1: 4 \mathrm{~cd}$ het die $\mathrm{T}$ (extus)

$\mathrm{R}$ (eceptus) tweemaal dieselfde werkwoord vir "verwelk"; die AB gebruik twee verskillende, nl. „kwyn weg” en „verwelk”. So maak reeds die Septuaginta, en dit is waarskynlik dat in die Hebreeus i.p.v. die eerste maal umlal gelees moet word dalal of 'n ander werkwoord vir verwelk wat met $n \mathrm{~d}$ begin. Moontlik het ons hier egter in $A B$ met $n$ verfraaiing in die vertaling te doen, wat minder wenslik is ( sien ons artikel „Beginsels van Bybelvertaling", H.T.S. II, 3, bl. 115 vv., veral bl. 128, vertaalreël 3).

n Tweede afwyking van die TR gee die $A B$ in $1: 12 \mathrm{~cd}$ waar we aberù gelees word i.p.v. we abar we-, of in vertaling ,en hulle vergaan" i.p.x. ..en hy vergaan en". Die derde afwyking vind ons in 2:1 waar die $\mathrm{AB}$ i.p.v. „verstrooier" (Hebr. mēphiç) lees „verwoester" (Hebr. mappiç). W'as die eerste twee afwykings van die TR heeltemal geregverdig, die laasgenoemde is minder verdedigbaar en seker is dit heeltemal verkeerd om in vs. 15 die Hebreeuse woo:d belija'al dan ook weer met "verwoester" te vertaal.

Die vierde teksemendasie wat die $\mathrm{AB}$ aanbring staan in 2:13 waar ,,jou strudwaens" gelees word i.p.v. "haar (of sy) strydwaens". Die ryfde kom roor in 3:8 waar die Hebr. teks "van see is haar muur" verander is in .,waters in haar muur". Die twee laasgenoemde teksveranderings is ongetwyfeld geregverdig. Maar dan kan ons nie meer sê dat die Afrikaanse Bybelvertaling die Textus Receptus volg nie. Dis merkwaardig dat die ou Statevertaling in al hierdie vyf gevalle wel die TR gevolg het, al is die sin daardeur dan ook minder begryplik.

Die belangrike vertaalreël dat in vertaling in ongewone volgorde van woorde in die origineel deur $n$ ongewone volgorde in die vertaling moet weergee en so die beklemtoning wat hierdie woorde daardeur kry inaggeneem moet word (sien aangehaalde artikel, bl. 128, vertaalreël 5) is slegs in $n$ aantal gevalle deur die $A B$ in praktyk gebring. So vertaal die $A B$ in $1: 2$ tereg nie „Die HERE is 'n jaloerse God en n wreker ens." nie maar: 'n Jaloerse God en 'n wreker is die HERE'. Ook in $1: 3 \mathrm{~b}$, en $6 \mathrm{~d}$ word 'n minder gewone volgorde 
behou en veral verdienstelik is die nakom van die vertaalreël in $2: 4$, waar die stylvorm van die chiasme of kruisgewyse plaatsing van woorde mcoi inaggeneem is. Maar waarom dan nie konsekwent hierdie reël gevolg nie? Dis veral in hierdie opsig dat ons hierbo gegewe vertaling probeer om die skoonheid en krag van die oorspronklike noukeuriger weer te gee. ${ }^{2}$ )

Dan is daar ook verskillende gevalle waarin gesondig is teen die reël wat veral by 'n Bybelvertaling nakoming verdien, dat waar ' $n$ woord of woorde van 'n selfde stam in die origineel meermale herhaal word, in die vertaling dieselfde moet gebeur, terwyl andersyds woorde van verskillende stam deur verskillende woorde weergegee moet word (sien vertaalreël 6 in bogenoemde artikel). Nou word in $1: 11 \mathrm{c}$ en $15 \mathrm{f}$ dieselfde woord belija'al gebruik in vs. 11c letterlik ,'n belialsraadgewer", in vs. $15 \mathrm{f}$, die belial(sman)". Die AB vertaal in die eersgenoemde vers ",wat verderflike planne gemaak het", in die tweede ,.die verwoester" (op die beswaar teen hierdie vertaling is reeds hierbo gewys); ons stel voor "wat snode planne gemaak het" en dan in vs. 15 ,"die snoodaard"; mens sou ook kan kies ,,wat bose planne bemaak het" en .,booswig". 'n Vertaling ,.,snoodaard" of ,,booswig" druk veel beter die afkeuring van die profeet oor die optrede van die wêreldmag uit as ,die verwoester.

n Dergelike geval het ons in die drie in die Hebreeuse allittererende en assonerende woorde aan die begin van $\mathrm{H}$. 2:10 büqã ùmebùqã ûmebullāqā in $\mathrm{AB}$ weergegee met ,,Leegheid, ontleding, vernieling!" waarby die laaste woord die stylverskynsel bederf. Deur die hierbo voorgestelde vertaling: ,Woestheid, woesteny, verwoesting!" word die klank- en woordspel behou en die stam van die eerste twee woorde op dieselfde wyse vertaal as in $\mathrm{H}$. 2:2c. In $\mathrm{H}$. 3:3 gebruik die $\mathrm{He}$ breeus in die laaste twee reëls dieselfde woord, die $A B$ vertaal dit egter eers met "lyke" en dan met "dooie liggame”, waardeur die eentonige krag van die herhaling bederf word. In die laaste reël van $\mathrm{H}$. 1:19 staan in die Hebreeus dieselfde woord as in die voorlaaste van H. 1:15, dan moet ons dit soveel as moontlik met dieselfde Afrikaanse werkwoord vertaal; die spotklaaglied aan die einde van die profesie gryp hier terug op die bedreiging aan die einde van die eerste hoofstuk. Deur op sulke skynbare kleinighede te let, kan dikwels belangrike gevolgtrekkings insake die eenheid en egtheid van 'n profesie gemaak word. In die interessante beeldspraak van die sprinkane in $\mathrm{H}$. $3: 15$ is die Hebreeuse volgorde: voetgangers, voetgangers, treksprinkane: waarom die $\mathrm{AB}$ hierdie volgorde verander het, is my nie duidelik nie.

2) Vgl. ons vertaling in $H .1: 4 b, 6 a, 7 a, 9 b, 14 c, 15 a, H .2: 3 c, 13 d, H$. 3 : 8e. $10 \mathrm{~cd}, 13 \mathrm{~cd}, 19 \mathrm{ab}$. 
Op enkele minder noukeurige vertalings in die $A B$ wil ek nog kortliks die aandag vestig. In $1: 3 \mathrm{c}$ is ,wind" 'n te swak vertaling van die Hebreeuse woord, wat 'n warrelwind aandui. In vs. $6 \mathrm{~d}$ is ,.voor Hom" minder juis; eintlik staan daar „vanweë Hom”. In 2:5d lyk my die opvatting van die $\mathrm{AB}$ onjuis; daar is hier sprake van die oprig van die stormdak deur die aanvaller. nie deur die verdediger nie. In $3: 18 \mathrm{~b}$ gee die vertaling ..jou edeles hou hulle stil" nie die regte indruk nie; dis asof hulle nog lewe, terwyl die bedoeling is om hulle voor te stel as in die doodslaap neerleeende. In die volgende vers lyk my die vertaling "saamklap van die hande" beter as "saamslaan". want die profeet bedoel die leedvermaak van die volke oor die cndergang van die verdrukkernasie tot uitdrukking te bring.

Waar ons verder van die gebruiklike AB-vertaling afwyk was die rede ' $n$ nouer aansluiting van die Hebreeuse woordgebruik en hier en daar ook aan die ritme van die Hebreeus van Nahum wat volgens algemene erkenning van so $n$ hoë digterlike gehalte is. Dat in 3:9 Libeërs in die $A B$ staan i.p.v. Libiërs is waarskynlik 'n drukfout. Afwykings van die Textus Receptus en teksemendasies is hierbo deur halwe aanhalingstekens kenbaar gemaak. In vier gevalle het ons die teksveranderings van die $A B$ oorgeneem, in een geval egter nie $(2: 1)$. Met ander eksegete meen ons dat daar nog vyf plekke is waar die oorgelewerde teks deur ' $\mathrm{n}$ baie klein wysiging in die $\mathrm{k}$ nsonante of vokale $n$ veel beter sin gegee kan word. In H. 2:5 is jazkit ,hy ontbied" passender as jizkōr ", hy dink aan"; in H. 2:8 word i.p.v. mimẽ hi we- beter met die Septuaginta gelees mēmêhā; in H. 2:11 is ,,weiveld van die leeus" vir hierdie vleisetende wesens minder passend; ,jagveld" sou beter wees, maar Ninevé is nie hulle weiveld of jagveld nie, dit is die ander lande; lees dus i.p.v. mir'ê liewer méārat "hol". In H. 2:13c kom heel onverwags en in die beeldspraak van die leeuhol nie passend nie die strydwaens; die verandering van rikbēk in $r i b c ̧ e \bar{k}$ of $i r b \bar{e} k$ is heeltemal toelaatbaar. In die lazste reël van dieselfde vers skyn die beeldspraak verlaat te word, waar die gesante vermeld word. Prof. Obbink lees "jou gebrul". Of kan ons onder die "gesante", letterlik „sendings", „stuursels" die jagtende leeus verstaan wat onder leiding van die ou leeu die prooi van verskillende kante bekruip? In H. 3:9 is ,sy hulp beter as ,jou hulp' want hier word oor en nie tot Egipte se hoofstad gepraat en seker nie tot Ninevé nie.

Mag hierdie artikel daartoe dien om te laat besef hoe noodsaaklik dit is om die Afrikaanse Bybelvertaling aan ' $n$ ingrypende revisie te onderwerp en by alle waardering vir sy groot betekenis en waarde te bly arbei aan ' $n$ so getrou moontlike weergawe van die Bybelteks in ons eie taal. Hier lê 'n groot en dankbare taak te wagte vir ons jong Afrikaanse Ou- en Nieutestamentici.

B. Gemser. 